\title{
EACH (Excellence in Analytical Chemistry), an Erasmus Mundus Joint Programme: progress and success
}

\author{
Ivo Leito ${ }^{1}$ • Anu Teearu ${ }^{1}$ • Johan Bobacka ${ }^{2}$ - Jérôme Randon ${ }^{3}$ • Jonas Bergquist ${ }^{4}$ \\ Published online: 8 August 2019 \\ (C) Springer-Verlag GmbH Germany, part of Springer Nature 2019
}

\section{The rationale and need for a joint master degree programme in analytical chemistry}

A large fraction (estimated from 25 to $70 \%$ by different surveys) ${ }^{1}$ of the chemistry master's degree holders are employed within the area of analytical chemistry worldwide and it has been demonstrated that there is a shortage of well-educated analytical chemists in Europe. ${ }^{2}$ The need for educated chemists is even more serious in emerging economies, such as China, India, Mexico, Brazil and Vietnam, where chemical industry is booming: "...strong growth and huge domestic demand is attracting global firms in expanding their presence in the area". ${ }^{3}$ The growing need for qualified chemical analysis specialists is also well indicated by the active

${ }^{1}$ (a) American Laboratory 2006, 38, 32-34. (b) C. Tolond, RSC Careers Service, Trends in Remuneration Survey 2008.

2 (a) R. Salzer, Anal Bioanal Chem 2012, 402, 25-28. (b) R. Salzer et al Chem Eur J 2015, 407, 639-643. (c) A new survey started on Mar 1, 2017 (http://www.euchems.eu/esec2/).

${ }^{3}$ The Economic Times, Jun 8, 2013.

Jonas Bergquist

jonas.bergquist@kemi.uu.se

1 Institute of Chemistry, University of Tartu, Ravila 14a, 50411 Tartu, Estonia

2 Johan Gadolin Process Chemistry Centre, Laboratory of Analytical Chemistry, Åbo Akademi University, Biskopsgatan 8, 20500 Turku/ Åbo, Finland

3 Institut des Sciences Analytiques, UMR 5280, CNRS, Université Claude Bernard Lyon 1, University of Lyon, 5 Rue de la Doua, 69100 Villeurbanne, France

4 Analytical Chemistry, Department of Chemistry - BMC, Uppsala University, Box 599, 75124 Uppsala, Sweden attendance in practitioner-oriented training courses Europe-wide, e.g. the TrainMiC programme, ${ }^{4}$ as well as the popularity of the respective MOOCs. ${ }^{5,6}$

Partly, this shortage has been caused by the significant changes that have, during the recent years, taken place worldwide in the areas of measurements, testing and chemical analysis. Some examples: an increase of importance of quality assurance (quality management system, accredited according to international standards, e.g. ISO/ IEC $17025: 2017^{7}$ or GLP, is now a must in laboratories) and metrology ${ }^{8}$ aspects (estimating measurement uncertainty, as the main quality characteristic of analytical results is now a must), emergence of new analytical techniques and more stringent requirements by legislation. A number of novel analytical techniques have become widespread in modern analytical chemistry: LC-MS for trace organic contaminants, ICP-MS for trace elements, different sensors, etc.

Up to now, the higher education sector in the whole world has generally been unable to respond adequately to the changing needs of the chemical industry and analysis community. ${ }^{2}$ This is demonstrated, e.g. by the fact that around two-thirds of European chemical companies have difficulties in filling vacancies. ${ }^{2}$ The reasons are, above all, lack or insufficient coverage of the following topics in the master programmes focusing on analytical chemistry: metrology and quality topics (such as traceability,

\footnotetext{
${ }^{4}$ TrainMiC - Training in Metrology in Chemistry (http://www.trainmic.org/) ${ }_{6}^{5}$ MOOC: Massive Open Online Course.

${ }^{6}$ See, e.g. http://each.ut.ee/EACH/measurement-uncertainty-online-coursemooc-successfully-finished/ and https://sisu.ut.ee/measurement/what-ourparticipants-say

${ }^{7}$ ISO/IEC 17025:2017 General requirements for the competence of testing and calibration laboratories. ISO, IEC, 2017.

${ }^{8}$ Metrology is the science of measurements and addresses first of all the correctness and quality of measurement procedures and measurement results. Metrology in chemistry is metrology applied to analytical chemical measurement.
} 
measurement uncertainty), socio-economic aspects of chemical analysis and newly emerging areas of analysis, often on the borderline of analytical chemistry and other disciplines (e.g. autonomous and miniaturized analytical devices, determination of nanoparticles in environment, in vivo microanalysis in living cells, modern IT approaches in chemical analysis). Even if such topics are included in some European chemistry study programmes, the instruction usually takes place in the respective native language, not in English, thus not supporting the international attractiveness of EHEA.

\section{EACH description specifically, partners, web page, and contact information}

\section{General}

The master's programme Excellence in Analytical Chemistry (EACH https://www.analyticalchemistry.eu) has been designed with the main objective to fill the abovementioned gap by providing top quality and "full package" education integrating the fundamental and practical skills in modern analytical chemistry with metrological, quality assurance, and socio-economic aspects as well as the emerging areas of analytical chemistry. The graduates of the programme will have both strong fundamental knowledge of analytical chemistry and measurement science, knowledge about the emerging areas of analytical chemistry, as well as applied knowledge of the methods of analysis and practical skills for their usage. The programme has been designed in close contact with stakeholders (and future employers).

The EACH programme was initially inspired by the Euromaster-labelled ${ }^{9}$ consortium Measurement Science in Chemistry, focusing on the measurement science and quality aspects of analytical chemistry currently uniting 10 universities from 7 countries. Three partners of this proposal-University of Tartu (UT) Estonia, Claude Bernard University Lyon 1 (UCBL) France and associated partner University of Oulu, Finland - are also partners of MSC. The MSC consortium is a "less joint" and less formalized than $\mathrm{EACH}$ but it proved that excellence in teaching (analytical chemistry) can best be achieved in cooperation, as more integration and complementary competence of partners is needed to stand out academically in the world context. As a result, the EACH programme has been created and is running since 2015 .

The programme presents an opportunity to learn modern analytical chemistry at four leading European

\footnotetext{
$\overline{9}$ Please see more information at http://www.msc-euromaster.eu/ and http://ectn.eu/committees/label/labels/
}

universities-University of Tartu (UT) Estonia, Uppsala University (UU) Sweden, Claude Bernard University Lyon 1 (UCBL) France, Åbo Akademi University (AAU) Finland - under the guidance of leading European analytical chemistry educators and practitioners. These four full-partner universities of EACH have created a coherent, compatible and international learning environment, where mobility is well embedded to the programme's structure. Integrated mobility (see Scheme 1) enables students to get access to technologies and knowledge practised in the four universities, which broadens their vision of contemporary analytical chemistry and enables acquisition of a diverse skillset. The complementary nature of EACH partner universities' strengths (see below) justifies the mandatory mobility - studying at two of the four partner universities will give the strong added value by combining a solid fundamental analytical chemistry and metrology education with a strong practical application component. The graduates acquire a set of field-specific competences and skills plus generic competences required of any analytical chemist suitable for today's job market.

\section{First study year and internship}

The three study tracks of EACH are presented in Scheme 1. The students spend their first study year at UT (also referred to as the first-year university) learning the fundamentals of analytical chemistry (including the mainstream practical skills for working in an analytical laboratory), analytical quality and metrology in chemistry as well as the socio-economic aspects of analytical chemistry. Starting at UT ensures a solid foundation for the students' analytical chemistry education. The advantage of having all first-year students at the same university is that their knowledge and skills are of the same level to successfully continue at the second-year universities. In order to further support this, a bridging course addressing specifically the skills is now an important part of the programme. That course mainly aims at helping students who come from countries with very limited lab possibilities at universities. In that course, the main lab instruments (volumetric ware, balances, etc.) and skills (handling liquids, weighing, etc.) are taught, so that the students would be well prepared for the more sophisticated lab courses later in the programme.

In the case of the UU and AAU study tracks, the first year ends with the internship placement (often at one of the associated partners), which is a mandatory component of the programme. The internship typically takes place in the summer between the first and the second year, while the student is still affiliated to UT. Its duration is usually between 1 and 3 months, depending strongly on the possibilities and wishes of the internship provider. The official 


\section{E Cxcellence in Analytical Chemistry ${ }^{* * *}$ Co-funded by the Erasmus Mundus Joint Master Degree

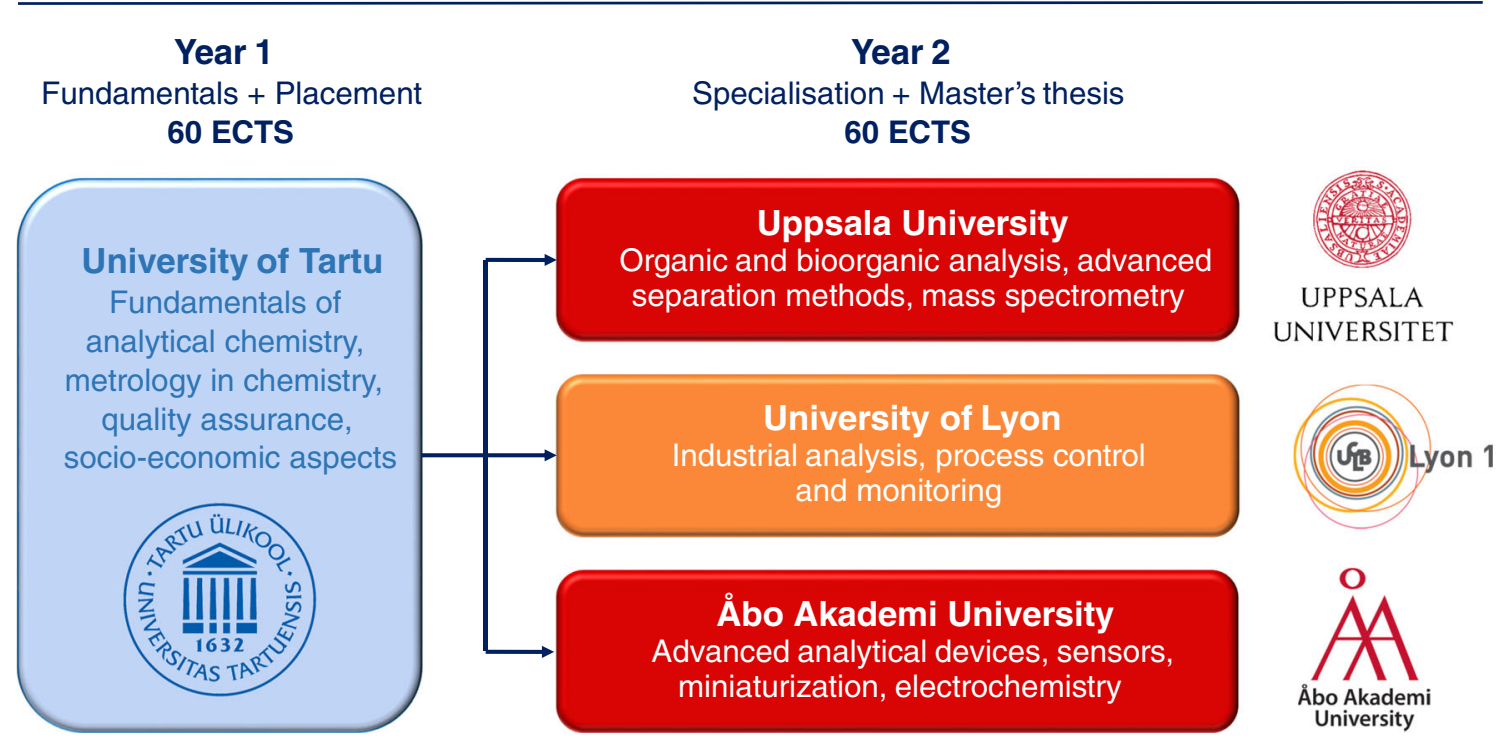

Scheme 1 Study tracks of the EACH programme

status of the student at the internship provider (e.g. trainee or part-time employee) is also strongly dependent on the internship provider. The internship is aimed to complement theoretical studies with practical skills, ability to work autonomously in real-life surroundings, communicate with experts in the field and to prepare students for their master thesis works.

The UCBL study track differs by including a more voluminous internship, which is done during the second year of March to September (see Table 1) when the student is affiliated to UCBL. This internship is usually closely linked with their thesis work.

\section{Second study year}

The second study year is specialisation-oriented and is spent either at UU, UCBL or AAU (also referred to as second-year universities). Each university's strengths are in one of the branches of applied analytical chemistry:

- UU: Organic and biomedical analysis, separation methods and mass spectrometry, especially as applied to biological targets.

- UCBL: Industrial analytical chemistry and process control.

- AAU: Electrochemical sensors, electroanalytical chemistry, advanced analytical devices.

Detailed module scheme of the programme is given in Table 1.

\section{Progress of the programme}

The EACH programme is managed by a Consortium Committee (CC), including the Academic Coordinator, the Academic Board (key academics from the four universities plus one student from each intake) and the Management Board (key administrators of the four universities). The management is supported by an Advisory Council (representatives of the associated partners plus other members, such as EACH graduates) and a Secretariat.

Student candidates can apply to the EACH programme annually from mid-November to mid-January. The applicants must have a bachelor's degree (or equivalent) encompassing at least 60 ECTS in chemistry or chemical engineering and 20 ECTS in mathematics and/ or physics. The candidate must also submit a proof of English language proficiency (IELTS, TOEFL, etc.) and a motivation letter. After an initial screening of the submitted documents, the applicants are ranked based on the (i) average grade of the previous study level, (ii) motivation letter and (iii) results obtained in an online test on problem solving. The admission criteria of the candidates are specified in detail on the programme website (https:/each.ut.ee/EACH/admission-requirements/).

Since its start in 2015, the EACH programme has attracted talented students from many parts of the World. The annual intake numbers of students have been between 17 and 19. The map below (Fig. 1) shows the origin of the students included so far in the EACH programme.

In the application form, the students are guided to select the study track they are interested in, i.e. UT- 
Table 1 Structure of the EACH programme

$\begin{array}{lll}\text { Module name and } \quad \text { Module contents } & \text { Focus and learning outcomes of the modules }\end{array}$

volume in ECTS

Year 1, 60 ECTS

General analytical chemistry module, T1 (21)

Metrology and quality management module, T2 (9)

Socio-economical module, T3 (12)

Internship placement, IP (6)

Language and elective module, T4 (9)

Optional courses (3)

Year 2, 60 ECTS
9 ECTS lectures, 6 ECTS seminars and 6 ECTS lab. The lab course embraces the most common chemical analysis techniques (titration, electrochemistry, GC, LC, GC-MS, LC-MS, different spectroscopies). All lab works are done with real samples and involve sample preparation

A 6 ECTS course on metrology of chemical measurements, which includes lectures seminars and practicals (solving problems on computer) and a 3 ECTS lecture course on quality management

Courses bridging the world of measurement with economy, law or environment. Some of them have lab and/or teamwork component

Student acquires understanding of the analytical chemistry issues in a professional environment at industry, research institution or a professional laboratory as well as the knowledge and skills for performing specific tasks
University of Tartu (general analytical chemistry, metrology in chemistry, quality assurance, socio-economical aspects, training placement)

Student acquires the basic knowledge and skills in analytical chemistry: (1) general principles of chemical analysis: chemical analysis workflow, analysis procedures, their characteristics; skills for evaluating the analysis results; general principles of chemical thermodynamics and transfer processes; (2) main methods of chemical analysis (gravimetry, titrimetry, electrochemistry, chromatography, mass spectrometry, optical spectroscopic methods) and the underlying processes (precipitation, partition, chemical equilibria, quantum and electronic processes in atoms and molecules); (3) analysis objects and samples, principles and main methods of sample preparation (digestion, extraction, etc.)

Student acquires the knowledge of the main metrological concepts (traceability, measurement uncertainty) and approaches (validation of analysis procedures, reference materials, interlaboratory comparisons) relevant to chemical analysis, as well as the related practical skills (experiment planning, data treatment) in their application to analytical chemistry (metrology in chemistry). Student learns about the economic and legal aspects of analytical chemistry and its role in contemporary society; student knows the principles of operation of an accredited quality system and is able to work within it

Student has the understanding of the importance of analytical chemistry for society from the economic and legal point of view, knows the cost structure of chemical analysis and is able to understand legislative acts related to chemical analysis

This module is important for (1) preparation of the student for future employment and (2) possible selection of the master's thesis topic. Upon completion of the module, the student: (1) Has understanding of the analytical chemistry issues in a professional environment at industry, research institution or a professional laboratory; (2) has the knowledge and skills for performing certain tasks in professional environment and use the lab equipment; (3) understand the quality norms and standards practised in a particular field; (4) has experienced working in teams and in professional non-educational setting

Student acquires (1) additional knowledge according to his/her interests and (2) language knowledge. The levelling course in chemistry as well as the introductory language course (Swedish, French, Finnish or Estonian) is included in this module. In the beginning of the first semester, there is an introductory test to identify lower level students who need the levelling course.

Student who has passed the module has intermediate knowledge in some specific field of chemical analysis or physical measurements; basic proficiency in one of the languages spoken in the 2nd year universities and is familiar with the main cultural characteristics of the countries where studies take place

Optional courses can be about any topic of interest

Uppsala University (advanced separation methods and organic analysis) 
Table 1 (continued)

$\begin{array}{lll}\text { Module name and } \quad \text { Module contents } & \text { Focus and learning outcomes of the modules }\end{array}$

volume in ECTS

Applied chemical analysis of complex samples, U1 (15)

Advanced mass spectrometry, U2 (15)

Swedish language, U3 (5)

Industrial analysis, L1 The main target of the master programme "Industrial analysis" (30)

French language, L2 (5)

Electroanalysis module, A1 (25)

The course provides in-depth knowledge of advanced methods for sampling, sample preparation and separation, and how these are combined with final determination methods for complete analysis procedures and gives knowledge of methods for analysis of variation contributions and multivariate evaluation. The course will also develop your ability to independently and critically choose methods for solving complex analysis problems obtained mainly from people, medicine, industry and the environment

Overview of modern instrumentation in high-resolution mass spectrometry including Fourier transform cyclotron resonance MS (FTICR), Orbitrap MS and imaging MS. Emphasis is placed on the conditions and opportunities offered for different combinations of separation methods, imaging techniques and mass spectrometry, where both qualitative and quantitative analytical aspects are considered. Tools for analytical data evaluation for the issues

is to answer the question: How to perform measurement in an industrial plant? It is paramount to monitor and optimize industrial processes in the chemical, petro-chemical, pharmaceutical, biotechnological, nuclear or food industries with integrated high-performance analytical methods directly on the production line. The analytical methods employed must not only support the control and optimization of processes, they also have to be fast, and easy to implement.

The implementation of analytical methods in an industrial context requires a variety of skills which are related to general and industrial analytical chemistry, process engineering, advance quality control, Information technology applied to manufacturing, risk management, health and safety

Student acquires basic knowledge in electrochemistry (5 ECTS) and deep insight into chemical sensors (5 ECTS) by attending lectures and by performing calculations and laboratory exercises. Student gets familiar with analytical chemistry research by performing a special project in analytical chemistry (10 ECTS), which involves extensive experimental laboratory work, literature search and writing of a report. Student also participates in seminars in
Methodology and practical application of complete analysis procedures including advanced methods for sampling, dissolution procedure, extraction, fractionation, enrichment of components from composite samples, separation methods, final determination and evaluation of results. Analysis of variation contributions in results from different sources with ANOVA. Evaluation of results with multivariate methods such as PCA, PLS. Scientific literature in analytical chemistry.

The teaching is given in the form of lectures, project-oriented laboratory work individually and in groups, seminars, mini symposium and possibly study visits.

Laboratory work, projects, seminars, mini symposium and possible study visits are compulsory

The module will give practical and theoretical knowledge and skills of modern analytical separation (chromatography, electrophoresis) combined with detection using mass spectrometric methods. The teaching takes the form of lectures, lessons, group discussions, laboratory work, demonstrations, seminars and communication training (oral and written)

Student who passes modules U1 and U2 is able to define the problem, choose the methods, test them and determine their characteristics, assess their suitability for the task and apply corrective actions in the subfield of separation science and organic analysis, including multimodal separation techniques and complex samples of biological importance

Students have the possibility to follow a course at intermediate level of the Swedish language

University Claude Bernard Lyon 1 (industrial analytical chemistry and process control)

Instrumentation for industrial analysis, sampling for industrial process, innovation and strategy for industrial analysis, communication and management, data transfer and data analysis.

Student who passes this module is able to define the problem, choose the methods, test them and determine their characteristics, assess their suitability for the task and apply corrective actions in industrial analytical chemistry and process control

Student has intermediate level of the French language

Åbo Akademi University (sensors, electrochemical analysis, advanced analytical devices)

Student acquires theoretical background and practical skills in electrochemistry and chemical sensors. Modern design and fabrication of electrochemical sensors as well as analysis of sensor measurement data are emphasized in laboratory exercises and seminars where student also becomes familiar with analytical chemistry research.

Student who passes the module is able to define the problem, choose the methods, test them and determine their characteristics, assess their suitability for the task and apply 
Table 1 (continued)

$\begin{array}{lll}\text { Module name and } \quad \text { Module contents } & \text { Focus and learning outcomes of the modules }\end{array}$

volume in ECTS

analytical chemistry (5 ECTS) that include writing of an essay and giving an oral presentation

corrective actions in electroanalysis and electrochemical sensors, including their design, miniaturization and uses for different analytical tasks

Students have the possibility to follow a course at intermediate level of the Swedish language

(5)

All second-year universities

Master's thesis, MT (30)

(together with Winter school, WS)
Student develops practical skills in planning, executing and reporting of scientific or applied research project in the field of analytical chemistry.

At UU, the Master's thesis project (30 ECTS credits during 6 months) can be conducted either at the university, or at another university or governmental organization (e.g. Swedish Food Administration, Swedish Medical Product Agency), or as an $\mathrm{R} \& \mathrm{D}$ project in collaboration with an industrial partner. The project includes literature studies, experimental work and writing of a Master's thesis that is defended by the student before graduation in June every year. Each student has a main supervisor at the university, a subject specialist at the university, a supervisor at the research site, a student opponent, an external opponent from one of the partner organizations and two examiners (one from Tartu university and one from Uppsala University).

At UCBL, tuition periods (4 weeks) and project period (4 weeks) alternate throughout the first semester. Then the 6-month training takes place from March to September, in industrial companies or in governmental or university laboratory. Master thesis is based on literature survey, experimental design, experimental work. The defence is done in September with examiners from Lyon and Tartu.

At AAU, the Master's thesis project (6 months) can be a pure research project at the university or can be done as an R\&D project in collaboration with an industrial partner. The project includes literature studies, experimental work and writing of a Master's thesis that is defended by the student before graduation
Student, who has passed the module:

- is intimately familiar with one specific field of analytical chemistry both in terms of knowledge and skills;

- is able to evaluate and present analytical results, compose and present public presentations and present one's viewpoints, conclusions and generalizations and discuss them with experts in the field;

- knows the principles and requirements for scientific work and scientific ethics and is able to work according to these requirements.

- is able to put the results into a wider socio-economic perspective.

- is able to apply his/her skills and knowledge for problem solving in new/unfamiliar situations, within broader (multidisciplinary) context, in complex situations with limited information, under time pressure.

- is able to communicate his/her conclusions and justify them both to specialist and non-specialist audience.

- is able to learn in an autonomous way.

An important preparatory element of the master's thesis is the Winter School consisting of short courses on the emerging areas of analytical chemistry, discussions with lecturers and presentations by students about the progress of their master's theses
UU, UT-UCBL or UT-AAU. During the first semester at UT, the first-year EACH students will get more information about the second-year universities. After the first semester, the final decision concerning the study track is made at the annual Winter School that is organized during a week in January (Fig. 2). Winter Schools have been organized in Estonia (2016), Sweden (2017), France (2018) and Finland (2019). The next one will again be in Estonia (2020).

In addition to its scientific and educational role, the Winter School provides a unique opportunity for interactions between students, teachers and administrators of the EACH programme. Both first- and second-year students participate in the Winter School, allowing fruitful interactions among EACH students. At the Winter School, the second-year students tell about their experiences from the second-year universities (UU, UCBL, AAU), which further helps the first-year students to select their study track. The annual Winter School is also an important forum for the Consortium Committee (CC) meetings, where decisions are made regarding student selection and management of the EACH programme.

After their first year of studies in Tartu (Estonia), EACH students have a solid background in the fundamentals of analytical chemistry and move to Uppsala (Sweden), Lyon (France) or Turku/Åbo (Finland) for specialization in their second-year studies. During the second year, the students attend courses provided by the second-year university (30 ECTS), attend their second Winter School and complete their master thesis (30 ECTS). Every master thesis has at least two supervisors-one from the second-year university and one from the first-year university. Evaluation of the master's theses is carried out by a joint evaluation committee. 


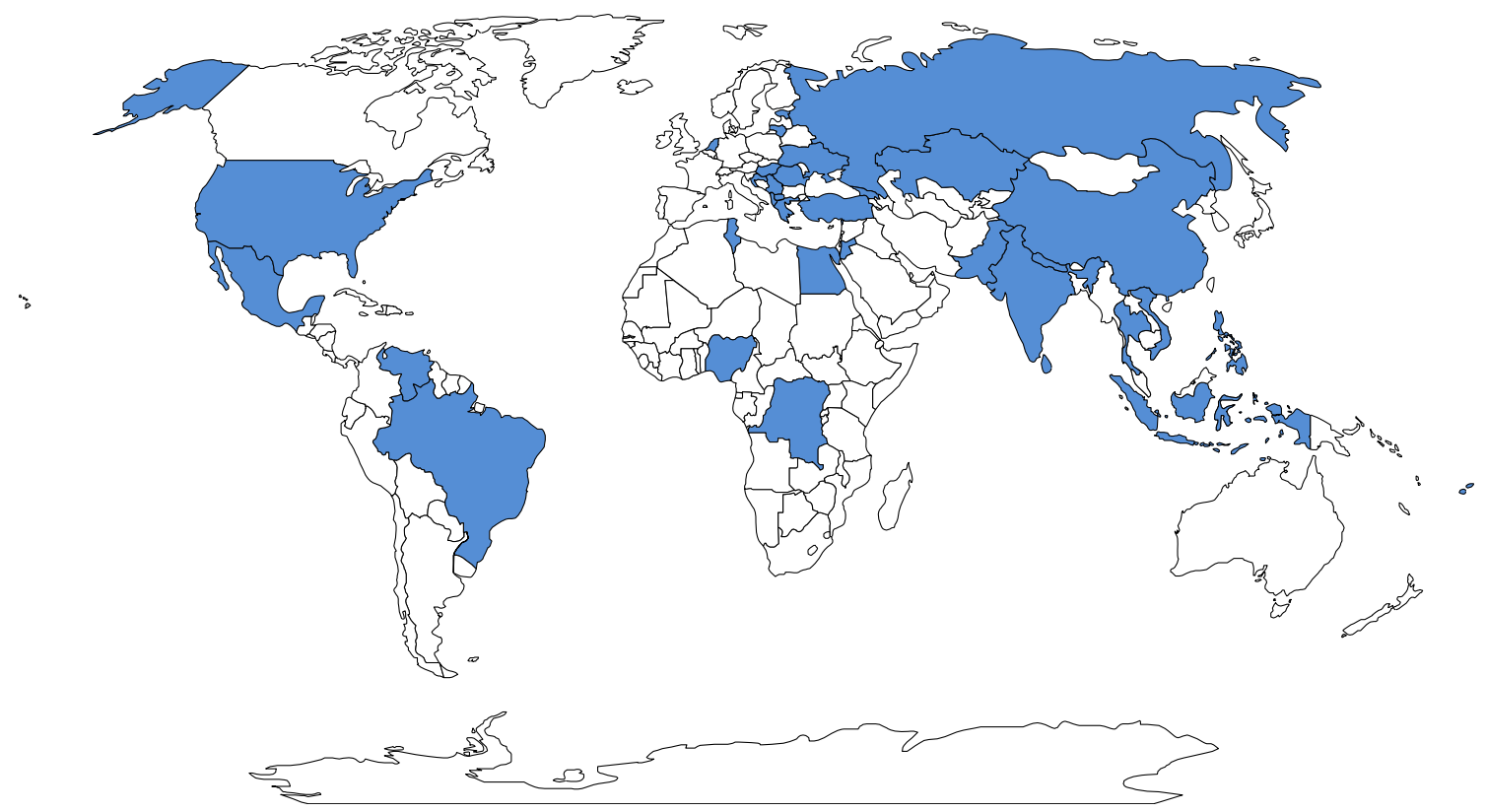

Fig. 1 The EACH World Map in spring 2019 showing the spread of the 36 countries from where students have been admitted to the programme so far (including Albania, Brazil, CD Congo - Kinshasa, China, Croatia, Egypt, Estonia, Fiji, Georgia, Greece, Hong Kong, Hungary, India,
Indonesia, Jordan, Kazakhstan, Lithuania, Macedonia, Mexico, Montenegro, Nepal, Netherlands, Nigeria, Pakistan, Philippines, Romania, Russia, Serbia, Sri Lanka, Thailand, Tunisia, Turkey, Ukraine, USA, Venezuela, Vietnam)
In addition to dedicated teachers available at UT, UU, $\mathrm{UCBL}$ and $\mathrm{AAU}$, the EACH programme benefits greatly from visiting scholars that lecture short courses either at one of the partners or at the Winter School. Involvement of visiting scholars in regular teaching and in Winter Schools spreads knowledge about the most recent scientific developments in analytical chemistry. Visiting scholars bring genuine added value to EACH in the form of expertise that is either (i) complementary to what is available at the partner universities, (ii) linked to emerging/frontier areas of analytical chemistry or (iii) linked to important "soft/generic" skills (team work, employability, ...). Furthermore, the visiting scholars help to give students the broadest possible view of analytical chemistry as a discipline, specifically from the "real life" perspective. Further information and application form for visiting scholars can be found on the programme website (https://each.ut.ee/EACH/for-visiting-scholars/).
Fig. 2 Group picture from the January 2017 Winter School at Lake Erken in Uppland, Sweden. Photographer: Jayaruwan Gunathilake Gamaethiralalage

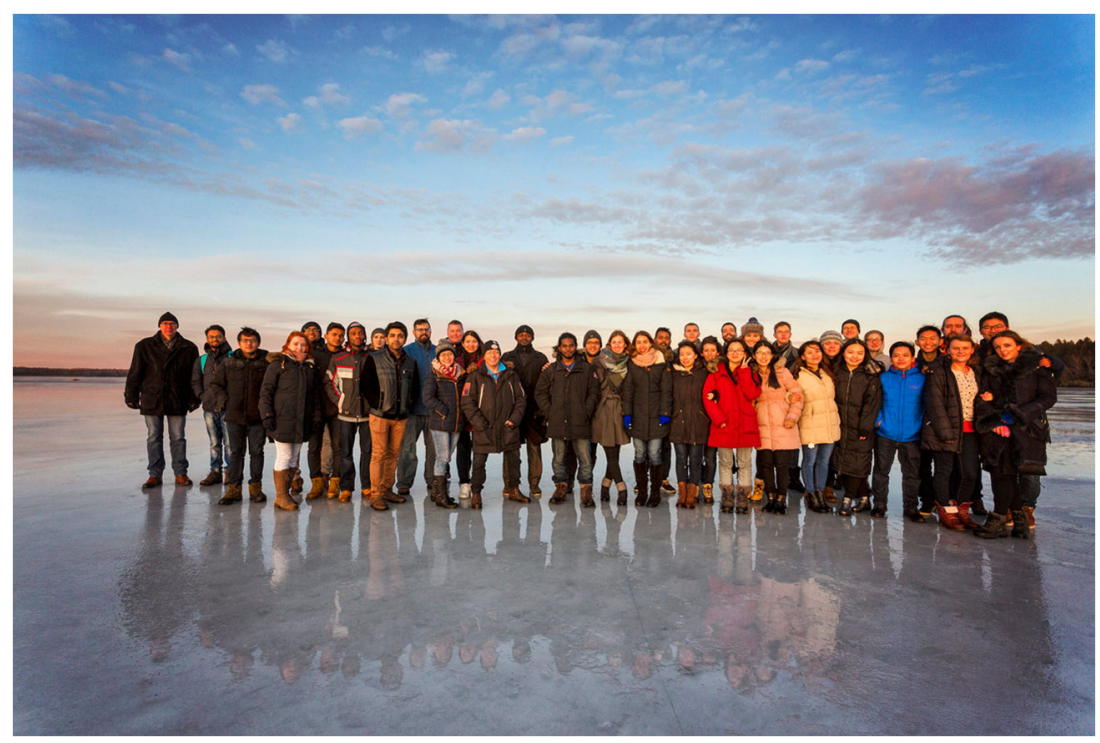




\section{Communication and collaboration with the surrounding academia, society and industry}

In the EACH programme, several non-academic public and private players participate as associated partners of the consortium. The industrial and laboratory partners from all four participating countries enable a strong link with the socioeconomic community. Some of them use analytical chemistry for production control (Tallinna Vesi, Arkema, Solvay, IFPEN, Axel'One), some develop and produce analytical devices (Bruker, Perkin Elmer, SRA, Antelia), some provide analytical services or carry out environment/food/monitoring, etc. (SYKE, EKUK, Terviseamet, RISE).

EACH has already had an interesting impact on the associated partner companies. They are interested in well-qualified analytical chemists with different cultural and linguistic backgrounds. This has already happened thanks to EACH and this impact is expected to become more pronounced with time. For example, the French companies linked to EACH as associated partners have said that they are interested in having more Russian-speaking interns due to their plan to broaden their activities in Russia. Additionally, industry partners have expressed interest to make more contacts with the students of South East Asia for making professional links in that region. Thus, as internship is an integral part of the programme, the foremost impact to be noticed is that awareness of the EACH programme spreads fast. Having the industry representatives lecturing in the programme enables them to be part of the programme and disseminate information on the programme in the professional circle.

\section{Where do the EACH alumni end up after examination? Employability of analytical chemists/EACH students}

An inventory of the graduated alumni from the EACH programme certainly shows that their potential for employability and future career in both academia and industry is very high. In total, $47 \%$ of the EACH graduates have continued into a $\mathrm{PhD}$ programme, and another $44 \%$ have found a job-among them $27 \%$ are employed in research projects in academia and $73 \%$ are employed by the industry.

A large majority of the students stay abroad directly after their graduation and continues their international career path, stimulated by the EACH programme. Some comments from students that have been enrolled in the programme can be found at the $\mathrm{EACH}$ webpage (each.ut.ee). The success of our graduates is also the success of the EACH programme. This has also been recognized by the European Commission who has decided to extend the funding of Erasmus Mundus scholarships for the EACH programme a second time.

\section{Future initiatives for the EACH programme}

Several procedures are foreseen to ensure regular and systematic monitoring of the programme delivery and academic results based on internal (at each partner university, consortium internal evaluation, evaluation by the advisory council) and external evaluations (National Quality Assurance, stakeholders quality valuation). One of the main tools used for assessment — students' feedback to courses and teaching - is accessible to the teachers delivering the course as well as the members of the Academic Board. The years of cooperation within EACH have enabled incorporating the experience and some student feedback into the development process of the EACH curriculum. In particular: the learning outcomes have been defined more accurately; a bridging course has been introduced to increase the practical part in the first year; more focus is now put on developing students' IT skills. However, even if it still is evolving and even if it is a very successful programme, EACH runs only with 4 major European partners. Such approach has now to be shared with other institutions across Europe and can be the starting experience of a new programme such as the Knowledge Alliances scheme, recently introduced by the EU in the framework of Erasmus+. ${ }^{10}$ Such alliance will be an innovative transnational project, which brings Higher Education Institutions and Businesses/ Enterprises together to work on common issues which have originally been addressed by EACH but now are approached on a larger scale.

Acknowledgements We first of all want to acknowledge all the very dedicated students and teachers of the EACH programme. Without their engagement there would not be any success of the programme. The EACH programme is co-funded by the Erasmus Mundus Joint Master Degrees action of the Erasmus+ programme of the European Union. The practical works of the first-year students are in part carried out using the instrumentation at the Estonian Center of Analytical Chemistry (www.akki.ee). The authors are thankful to Ülle Tensing, Magnus Strandås, Sofia Thorsélius, Ulla Bäckström, Heidi Karlsson, Sylvie Childs, Racha El Debs, Emilie Noguez, Urve Soonets, Kaija Murasov, Katre Suumann and Katrin Küünal for their kind assistance.

Publisher's note Springer Nature remains neutral with regard to jurisdictional claims in published maps and institutional affiliations.

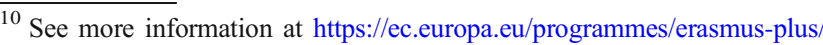
opportunities/knowledge-alliances_en
} 


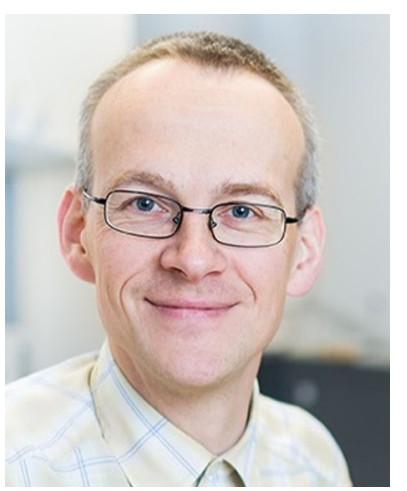

Ivo Leito obtained his $\mathrm{PhD}$ from the University of Tartu (UT) in 1998. During 20022005 he reorganized the UT Testing centre - a unit providing testing, measurement, analysis and training services to laboratories and industry and was its director. Since 2005, he has been working as Professor of Analytical Chemistry at the Institute of Chemistry, University of Tartu. His main research directions are on the borderline of analytical chemistry with other disciplines: chemistry of superacids and superbases; metrology in chemistry; liquid chromatography and mass spectrometry; sensors and their metrological characterization; applications of instrumental methods in analysis of historical objects. He teaches analytical chemistry and its metrological aspects at UT and has been involved in setting up several international educational activities, including the EACH programme. He has published 196 papers, $h$-index 41 (Scopus).

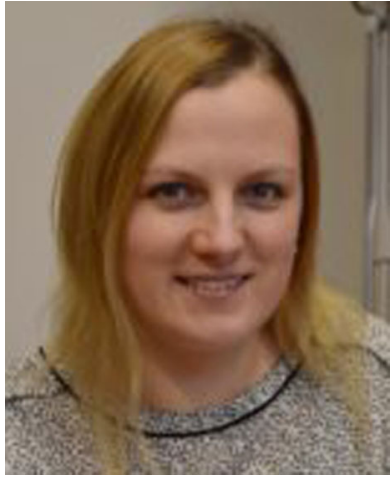

Anu Teearu, PhD, has been working as the administrative coordinator of the EACH programme since November 2016. In addition to helping to manage the EACH programme, she also is a support person for the students of the programme. Her background is in analytical chemistry, specializing mainly on the investigation of resinous materials with different analytical techniques, including ATR-FT-IR and FT-ICRMS. In 2017, she obtained her $\mathrm{PhD}$ in chemistry from the

University of Tartu.

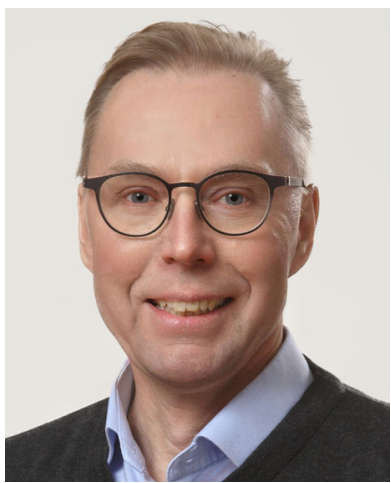

Johan Bobacka, D.Sc. (Tech.), is Professor in Analytical Chemistry and head of the Laboratory of Analytical Chemistry at Åbo Akademi University. Research in his laboratory is part of the Johan Gadolin Process Chemistry Centre, a centre of excellence at Åbo Akademi University. He main research activities are in the area of electroanalytical chemistry and electrochemical sensors with special emphasis on the development of solid-contact ion-selective electrodes, solid-state reference electrodes and novel transduction principles for ion sensors. He is an editor of Sensors and Actuators B: Chemical (Elsevier) and a member of the editorial advisory board of Electrochimica Acta (Elsevier). He is also a member of the editorial boards of Chemosensors (MDPI) and Current Topics in
Electrochemistry (Research Trends). He has published over 140 papers (h-index $=36$, Web of Science).

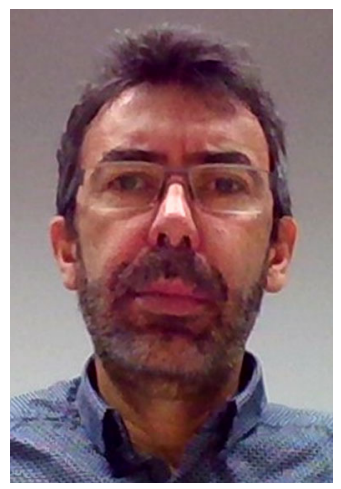

Jérôme Randon obtained his $\mathrm{PhD}$ from the University of Montpellier in 1991, investigating the effect of surface interactions in membrane-based separation processes. Then he moved to the University of Glasgow to design membrane surface modifications in order to tune hydrophobicity/ hydrophilicity balance. In 1994 he finally moved to Lyon and joined the Separation Science Research Group to work on analytical applications. Based on his background in materials science, he developed original miniaturized monolithic columns for separation and sample treatment based on metal oxides and he is now using such tools to perform ultrafast gas chromatography separations for on-line analysis. In 2004, when he got a professor position at the University of Lyon, he created a brand new master's degree specifically dedicated to "Analysis and Control" in order to fit the requirements of industry and the goals of research. This master's degree is running with more than 60 students graduating every year in analytical chemistry with strong relation with the job market. Link to his involvement in active teaching/learning development, he is also actually leading the chemistry education division of the French chemical society.

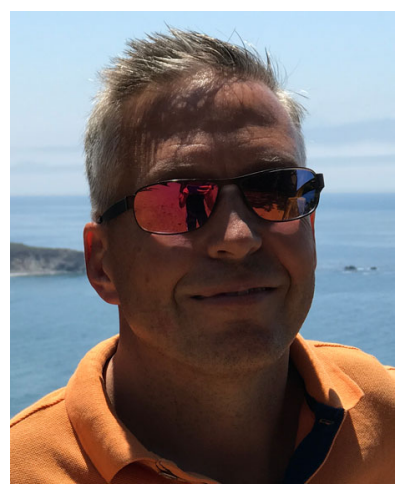

Jonas Bergquist, $\mathrm{MD}-\mathrm{PhD}$, is Full Chair Professor in Analytical Chemistry and Neurochemistry at the Department of Chemistry at Uppsala University, Sweden, Adjunct Professor in Pathology at the Department of Pathology, School of Medicine, University of Utah, USA, and Distinguished Professor in Precision Medicine, Binzhou Medical University, Yantai, China. His group is continuously developing general analytical tools for screening and discovery of biomarkers of pathological states. Technologies include all important links: identifying relevant clinical applications, advanced sampling and sample pretreatment, multidimensional liquid-based separation, high-resolution mass spectrometry (HRMS), and multivariate data analysis. Among other things, he focuses on exploring the neuroimmunology and endocrinology involvement in human disease by using proteomics and metabolomics with a special interest in cerebrospinal fluid studies and invasive sampling of inaccessible regions of the human body. He has currently published over 470 papers, with 9000-11600 citations (h-index 49/58 WoS/GS). 